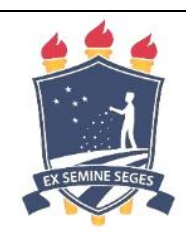

\title{
Avaliação da resposta imune de cães submetidos à vacinação contra cinomose associada ao estímulo pela acupuntura
}

\author{
[Evaluation of the Immune Response in dogs vaccinated against Canine Distemper associated to \\ acupuncture stimuli]
}

\section{"Artigo Científico/Scientific Article"}

\author{
Vanessa Alessandra Barros Portela ${ }^{1 *}$, Hugo César Viana Souza ${ }^{1}$, Marianna Ulbrik Guerrera ${ }^{1}$, \\ Thais Melquiades Lima ${ }^{1}$, Filipe Cássio Silva Lima ${ }^{1}$, \\ João Marcelo Wanderley Mendonça Uchôa Cavalcanti ${ }^{1}$, Rita Cássia Carvalho Maia ${ }^{1}$
}

\begin{abstract}
${ }^{1}$ Departamento de Medicina Veterinária, Universidade Federal Rural de Pernambuco (UFRPE), Recife-PE, Brasil. *Autor para correspondência/Corresponding author: E-mail: alessandra.barros.portela@ hotmail.com
\end{abstract}

\begin{abstract}
Resumo
A acupuntura é um dos métodos mais antigos da Medicina Tradicional Chinesa (MTC) que consiste na técnica de estímulo cutâneo com agulhas em locais pré-determinados (os acupontos), para prevenir ou tratar doenças, sendo usada na imunomodulação, onde atua na atividade hemodinâmica, aumentando a população e atividade das células Natural Killers, CD4+, CD8+, dentre outras. Por este motivo, acupuntura vem sendo utilizada como terapia complementar no tratamento de algumas doenças infecciosas, como a cinomose canina que é uma das doenças infecciosas mais importantes dos caninos, sendo endêmica no Brasil, altamente contagiosa, levando a quadro neurológico e morte. Os animais acometidos geralmente são os que não foram primovacinados. Este trabalho objetivou avaliar a resposta humoral de cães a partir da administração de diferentes doses de vacina contra cinomose associada aos estímulos nos acupontos IG4 (Hegu), VG14 (Dahzui) e E36 (Zusanli), e foi desenvolvido no Hospital Veterinário do Departamento de Medicina Veterinária da Universidade Federal Rural de Pernambuco. Foram realizadas imunizações em 18 cães, com idades variadas, distribuídas aleatoriamente em cinco grupos, sendo eles: Grupo I (G1) - três animais que receberam a dose usual de vacina, no total de $1 \mathrm{~mL}$, por via subcutânea na região do hipocôndrio direito; Grupo II (G2) - dois animais que receberam $1 \mathrm{~mL}$ da dose usual de vacina, por via subcutânea na região do hipocôndrio direito e estímulos nos acupontos IG4, VG14 e E36. Grupo III (G3) - quatro animais que receberam no total de $1 \mathrm{~mL} \mathrm{de} \mathrm{NaCl}$, por via subcutânea na região do hipocôndrio direito e estímulo nos acupontos IG4, VG14 e E36. Grupo IV (G4) cinco animais que receberam $0,2 \mathrm{~mL}$ da dose vacinal, por via subcutânea, na região do hipocôndrio direito e estímulo nos acupontos IG4, VG14 e E36. Grupo V (G5) - dois animais que receberam 0,2 mL da dose vacinal por via subcutânea na região do hipocôndrio direito. A avaliação hematológica foi realizada antes de administração de qualquer protocolo experimental (D0) e 12 (D12) dias após a administração dos protocolos. Os parâmetros avaliados foram o perfil hematológico e titulação de anticorpos anti-CDV. Os resultados obtidos demonstraram que a estimulação pela acupuntura elevou o título de anticorpos contra cinomose dos cães, em todos os grupos experimentais, até mesmo aqueles que não foram revacinados, mas que apresentavam um título médio anticorpos, demonstrando a real atividade imunoestimulante da acupuntura. Além disso, os parâmetros leucométricos demonstraram uma melhora na condição geral das defesas dos animais, uma vez que, em média, houve maior equilíbrio desses parâmetros após o uso da acupuntura. De acordo com nossos resultados, podemos concluir que a acupuntura pode se tornar uma técnica promissora no estímulo imunológico pré-vacinal de cães.
\end{abstract}

Palavras-Chave: CDV, anticorpos, imunização, Medicina Tradicional Chinesa.

\begin{abstract}
Acupuncture is one of the oldest methods of Traditional Chinese Medicine (TCM) which consists in a cutaneous stimulation technique with needles at predetermined locations, called acupoints, to prevent or treat diseases, also used in immune-modulation, where it operates in hemodynamic activity, increasing the
\end{abstract}


population and activity of CD4 +, CD8 + and Natural Killer cells, among others. Therefore, acupuncture has been applied as a complementary therapy for infectious diseases, such as Canine distemper one of the most important infectious diseases in the world, endemic in Brazil, highly contagious, leading to neurological disorders and death. Affected animals are usually those who have not been previously vaccinated. This study evaluated the immune response of dogs from the administration of different distemper vaccine doses associated with stimuli in IG4 acupoints (Hegu), VG14 (Dahzui) and E36 (Zusanli), and was conducted at the Veterinary Hospital of the Department of Veterinary Medicine at the Federal Rural University of Pernambuco, Brazil. Immunizations were performed in $18 \mathrm{dogs}$ with varying ages, randomly distributed into five groups, as follows: Group I (G1) - three animals received the usual dose of vaccine $(1 \mathrm{~mL})$ subcutaneously in the right hypochondrium region; Group II (G2) - two animals were given $1 \mathrm{~mL}$ of usual dose of vaccine subcutaneously in the right hypochondrium region associated with stimulation of IG4, VG14 and E36 acupoints. Group III (G3) - four animals received a total of $1 \mathrm{~mL} \mathrm{NaCl}$ subcutaneously in the right hypochondrium region associated with stimulation of the IG4, VG14 and E36 acupoints. Group IV (G4) - five animals received $0.2 \mathrm{~mL}$ of the vaccine dose, subcutaneously in the upper quadrant of the right region associates with stimulation of IG4, VG14 and E36 acupoints. Group V (G5) - two animals received only $0.2 \mathrm{~mL}$ of the vaccine dose subcutaneously in the upper quadrant of the right region. The leukometric evaluation periods were established before administration of any experimental protocol (D0) and 12 days after administration of the protocols (D12). The leukometric profile and titration of anti-CDV antibodies through chromatographic immunoassay for IgG antibody detection were evaluated. The results showed that acupuncture stimulation increased the antibody titers of the dogs against canine distemper in all experimental groups, even in those who did not receive the vaccine but had an initial middle antibody title, demonstrating the real immunostimulatory role of the acupuncture technique. Moreover, leukometric parameters showed that, in average, a balance was found in those parameters for animals that were submitted to the three acupuncture sections. According to our results, acupuncture can become a promising pre-vaccination immune stimulation technique in dogs.

Key-words: CDV, antibodies, immunization, Traditional Chinese Medicine.

\section{Introdução}

A cinomose canina é uma doença de caráter infeccioso, grave e letal maioria dos casos, que acomete cães e uma ampla variedade de animais terrestres e aquáticos (Carvalho et al., 2012). A infecção pelo vírus da cinomose (CDV) é mais frequente no momento da baixa de anticorpos maternos adquiridos pela ingestão de colostro, onde os animais não receberam a estratégia vacinal, portanto não há imunização adequada. Sabe-se, entretanto, que o vírus pode acometer os animais em qualquer faixa etária e que não há predileção por raça ou sexo, de modo que a imunossupressão ocorre indiscriminadamente (Freitas-Filho et al., 2014).

Após oito a dez dias do início da infecção, o CDV tende a migrar através da via hematógena ou via líquido céfalo-raquidiano (LCR), para o Sistema Nervoso Central (SNC) tendendo a resultar em lesões degenerativas e/ ou inflamatórias refletindo em sinais clínicos nervosos e muitas vezes de caráter irreversível e prognóstico reservado (Maclachlan e Dubivo, 2011; Aoki, 2014). Os sinais clínicos nervosos incluem paraplegia, hiperestesia, tremores, deambulação em círculos, convulsões parciais e generalizadas e mioclonias (Sherding, 2008). Não existe tratamento totalmente eficaz contra as sequelas neurológicas observadas na enfermidade, entretanto, terapias paliativas vêm sendo utilizadas para a redução da intensidade das sequelas, como a terapia celular e a acupuntura (Brito et al. 2010; Silva, 2011; Mangia et al., 2014; Marques, 2016).

$\mathrm{O}$ uso da acupuntura para o tratamento de enfermidades na Medicina Veterinária vem crescendo e se tornando uma alternativa palpável, uma vez que por meio de estímulos em pontos reflexos denominados de acupontos, resulta em ações imunoestimulantes, imunossupressoras, analgésicas e anti-inflamatórias (Matthiesen, 2004). Em cada acuponto ocorre alta confluência de terminações nervosas e sensoriais, concentração fibrilar neural, uma rede capilar bem desenvolvida, acúmulo de mucopolissacarídeos, além de encontrarem-se em contato íntimo com estruturas como nervos, vasos sanguíneos e tendões, demonstrando a diferença que existe na estrutura dos pontos de acupuntura com as demais partes do corpo, postulando sua especificidade no tratamento de doenças através dos estímulos cutâneos (Medeiros e Saad, 2009; Nunes, 2010). Alguns acupontos já tem ação conhecida no estímulo imune como E36, VG14 e IG4 (Bottecchia, 2005) e diversos efeitos são observados no uso da acupuntura, aonde uma gama de estudos vem confirmando a sua atuação positiva na modulação 
do sistema imune, principalmente em doenças alérgicas, infecciosas, autoimunes e síndromes de imunodeficiência (Yamaguchi et al., 2007; Takahashi et al., 2009; Kim e Bae, 2010).

$\mathrm{Na}$ Medicina Alopática, a utilização de vacinas é uma das formas encontradas para estimular componentes da defesa natural do organismo, configurando-se um importante artifício na ativação da defesa humoral e celular (Bottecchia, 2005; Greene, 2006). As vacinas produzidas com as amostras do vírus da cinomose são eficientes em induzir o estado de imunidade nos animais vacinados, protegendo-os contra a infecção natural (Biazzono et al., 2001). A partir de 1990, foram publicados os primeiros relatos de eventos adversos possivelmente associados à vacinação, como fibrossarcomas originados no local de aplicação da vacina em gatos (Hendrick e Goldschmidt, 1991) e o aumento da ocorrência de doenças autoimunes em cães, em especial a anemia hemolítica imunomediada (AHIM) (Durval e Ginger, 1996; Hogenesch et al., 1999), que levaram a alguns questionamentos sobre a segurança e a necessidade de reforços vacinais anuais (Smith, 1995). Desde então, diferentes abordagens para a elaboração do protocolo vacinal de animais de estimação têm sido publicadas e defendidas por entidades e associações veterinárias internacionais (Horzinek, 2006; Wolf, 2010). Na Medicina Tradicional Chinesa (MTC) não são descritas indicações quanto à aplicação de vacinas, porém sabe-se que a acupuntura tem ação constatada sobre o sistema de defesa natural dos organismos (Bottecchia, 2005).

Este trabalho tem por objetivo avaliar a resposta imune (leucometria e dosagem de anticorpos $\mathrm{IgG}$ ) a partir da administração de diferentes doses de imunógeno contra cinomose com associação de estímulos nos acupontos imunoestimulantes IG4 (Hegu), VG14 (Dahzui) e E36 (Zusanli) em cães da Região Metropolitana do Recife.

\section{Material e Métodos}

O projeto foi desenvolvido no Hospital Veterinário, do Departamento de Medicina Veterinária (DMV) da Universidade Federal Rural de Pernambuco (UFRPE), e nas residências de criadores da região metropolitana do Recife, onde foi realizada a vacinação (Canigen ${ }^{\circledR}$, Virbac) em 18 cães, sem predileção de raça, idade ou sexo, vacinados ou não, anteriormente ao início do experimento. Todos os procedimentos foram aprovados pelo comitê de ética no uso de animais (CEUA) da UFRPE, estando sob a licença de número 082/2014.

Os cães selecionados foram organizados aleatoriamente em cinco grupos, distribuídos da seguinte forma:

- Grupo I (GI) - Composto por três animais que receberam a dose usual de vacina, no total de 1 $\mathrm{mL}$, por via subcutânea na região do hipocôndrio direito, sendo considerado grupo controle positivo;

- Grupo II (GII) - Composto por dois animais que receberam $1 \mathrm{~mL}$ da dose usual de vacina, por via subcutânea na região do hipocôndrio direito e estímulos nos acupontos IG4, VG14 e E36;

- Grupo III (GIII) - Composto por quatro animais que receberam no total de $1 \mathrm{~mL}$ de $\mathrm{NaCl}$, por via subcutânea na região do hipocôndrio direito e estímulo nos acupontos IG4, VG14 e E36;

- Grupo IV (GIV) - Composto por quatro animais que receberam $0,2 \mathrm{~mL}$ de dose vacinal, por via subcutânea na região do hipocôndrio direito e estímulo nos acupontos IG4, VG14 e E36;

- Grupo V (GV) - Composto por cinco animais que receberam $0,2 \mathrm{~mL}$ da dose vacinal por via subcutânea na região do hipocôndrio direito.

Os parâmetros de exclusão consistiram em: animais vacinados com tempo inferior a seis meses, com parasitismo e com titulação para anticorpos IgG elevada. Apesar dos critérios, nenhum animal precisou ser excluído do experimento, mas em alguns casos, alguns proprietários retiraram o consentimento em continuar na pesquisa o que gerou no experimento um número diferente de animais por grupo experimental.

Os parâmetros avaliados em cada animal foram o perfil hematológico por técnica convencional de laboratório, realizado no Laboratório de Patologia Clínica do Hospital Veterinário da UFRPE, e a titulação de anticorpos anti-CDV avaliada por método qualitativo, por imunoensaio cromatográfico para detecção de anticorpo $\operatorname{IgG}$, sendo as titulações de $\operatorname{IgG}$ consideradas alta (1:128), média (1:16 1:64) ou baixa (abaixo de 1:16).

As amostras sanguíneas foram obtidas por venopunção da veia cefálica, no total de $2 \mathrm{~mL}$, em tubos com EDTA que foram remetidos ao Laboratório de Patologia Clínica da UFRPE para as avaliações. Os tempos de avaliação estabelecidos foram antes de administração de qualquer protocolo experimental (Dia 0 - D0) e no último dia após a última sessão de acupuntura (Dia 12 D12). Os estímulos pelas sessões de Acupuntura 
ocorreram no D0, D8 e D12 para os grupos experimentais GII, GIII e GIV e consistiram na inserção de agulhas estéreis para acupuntura de 0,30x40mm nos acupontos imunomoduladores, IG4 (Hegu), VG14 (Dahzui) e E36 (Zusanli), onde os animais ficavam agulhados por um período de 15 minutos, fazendo-se necessário o uso de um acuponto extra, o Yintang, capaz de causar efeito sedativo (Kim e Nam, 2006), para acalmar os animais mais agitados. Após o prazo estipulado de cada sessão, as agulhas eram retiradas e descartadas.

Para a análise estatística, foi utilizado o teste não-paramétrico Mann-Whitney, que é indicado para comparação de dois grupos não pareados visando verificar se pertencem ou não à mesma população.

\section{Resultados e Discussão}

Foram realizadas visitas as localidades na Região Metropolitana do Recife onde foi possível um primeiro contato com os animais, a anuência formal por parte dos proprietários, e assim, a realização da coleta inicial de sangue e aplicação dos protocolos vacinais e de acupuntura. Este momento foi considerado o dia inicial ou D0.

No D8, foi realizada a segunda sessão de acupuntura nos animais dos grupos experimentais GII, GIII e GIV, onde foi repetido o protocolo de cada sessão. No D12 de cada localidade, foi realizada a última sessão de acupuntura dos animais pertencentes aos grupos GII, GIII e GIV e efetuada a última coleta sanguínea para realização do hemograma e diferenciação entre os leucogramas de cada animal de todos os grupos experimentais.

Ao tabular os hemogramas da coleta do D0 e D12 de cada local foi realizada a frequência relativa acerca de cada célula sanguínea da série branca, envolvidos na defesa orgânica, avaliando as populações que se apresentaram dentro dos valores de referência (Jain, 1993; Kaneko et al., 1997) e comparativamente, a frequência dos animais que apresentaram os valores celulares fora dos valores padrões nos dois momentos (Figuras 1 e 2).

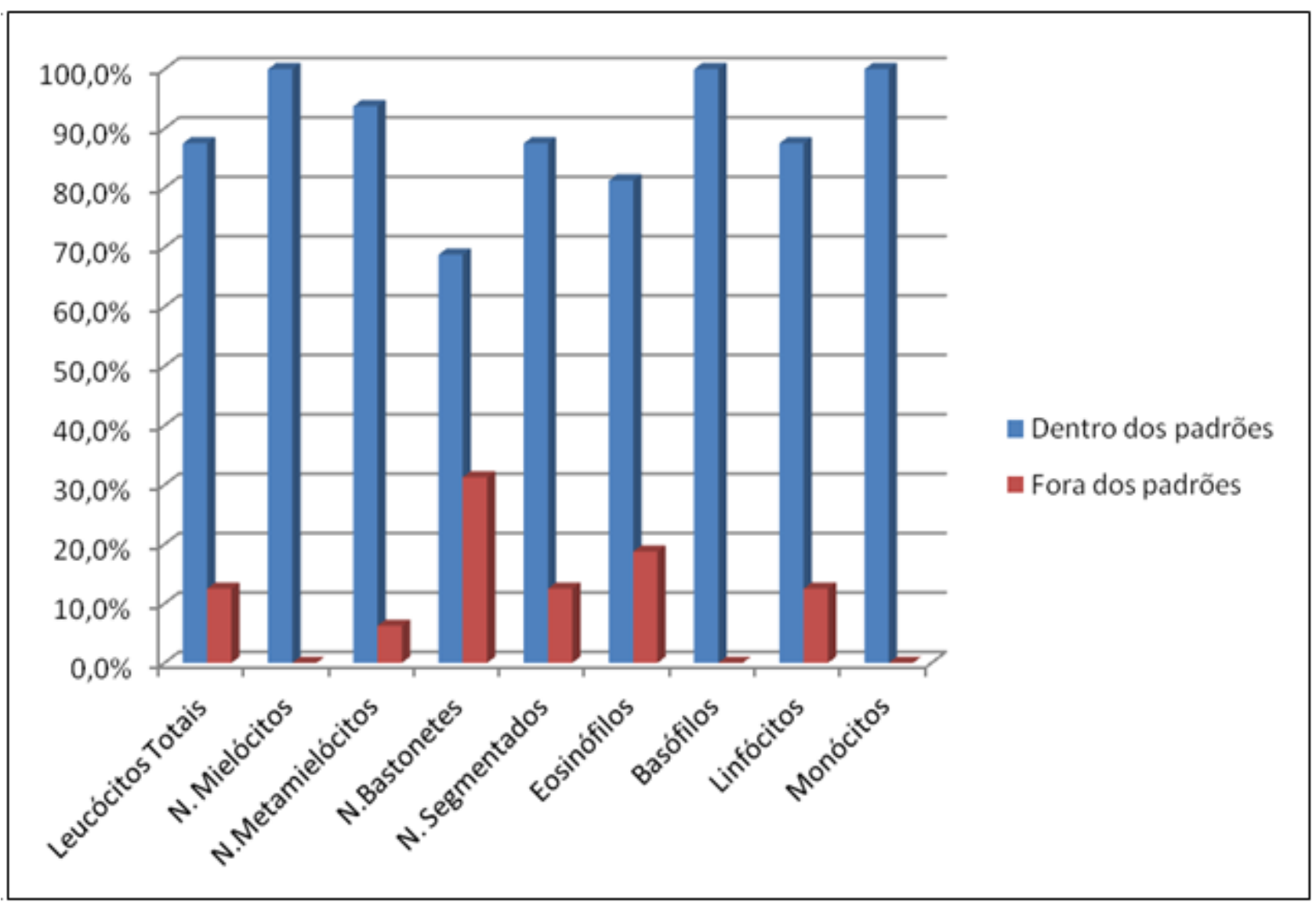

Figura 1. Dados referentes aos componentes do leucograma do sangue dos 18 animais coletados no dia inicial (D0). 


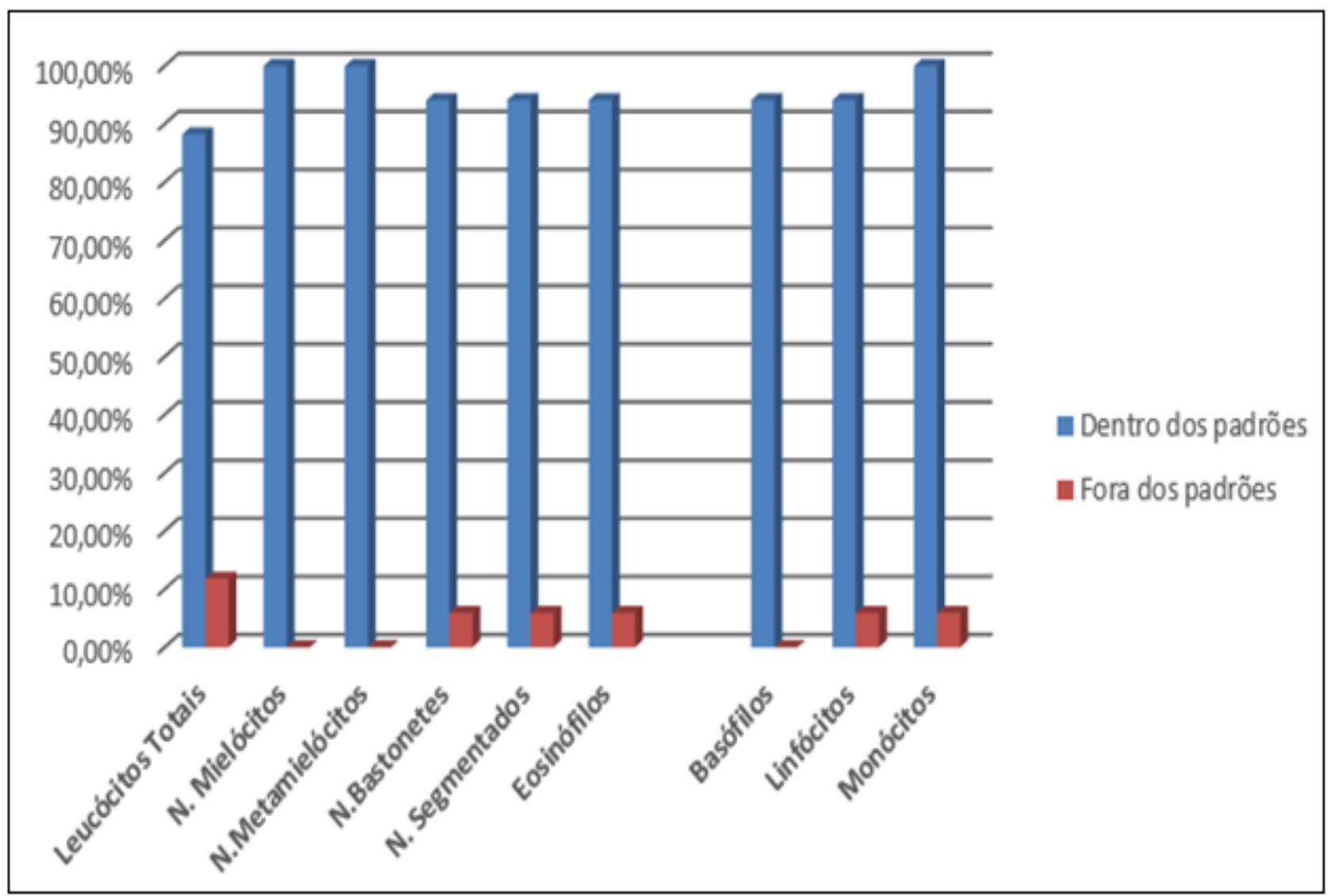

Figura 2. Dados referentes aos componentes do leucograma do sangue dos 18 animais coletados no $12^{\circ}$ dia (D12).

Observando as Figuras 1 e 2, pode-se observar um retorno aos níveis normais do leucograma, sugerindo que durante o período do experimento esses animais puderam responder imunologicamente a ponto de debelar injúrias secundárias e demonstrar o retorno aos valores de referência para a espécie 12 dias após o início dos protocolos. Tal achado corroborou com Drummond (2009), que afirmou que pode-se interpretar as alterações hemodinâmicas da série branca pós estímulo de acupuntura como consequente aumento da imunidade, onde o mesmo avaliou que tal parâmetro para cães em convalescência ocorre uma resposta expressiva principalmente dos leucócitos totais, levando a aceitar a acupuntura como grande aliada na ação terapêutica moduladora da hemodinâmica, prevenindo infecções secundárias e ocasionando uma melhora clínica.

A acupuntura desempenha funções imunológicas, com elevação da atividade humoral e celular (Lignon e Bottecchia, 2000), tendo como suporte dessa afirmativa os resultados expressos na Tabela 1, onde é possível observar que os animais que foram submetidos aos protocolos com acupuntura tiveram um mesmo estímulo e resposta produtiva de anticorpos anti-CDV que os animais que não tiveram o emprego da acupuntura, mas que receberam a dose completa da vacina, ficando, portanto evidente e comprovado estatisticamente a ação imune produzida via estímulos de acupuntura nos acupontos IG4, VG14 e E36.

Tabela 1. Dados referentes a titulação de anticorpos por animal.

\begin{tabular}{ccc}
\hline Grupo/Animal & D0 & D12 \\
\hline G101 & Média & Alta \\
G102 & Baixa & Alta \\
G103 & Negativo & Alta \\
G201 & Média & Alta \\
G202 & Média & Alta \\
G301 & Média & Alta \\
G302 & Média & Alta \\
G303 & Média & Alta \\
G304 & Média & Alta \\
G401 & Média & Alta \\
G402 & Média & Alta \\
G403 & Baixa & Baixa \\
G404 & Média & Alta \\
G501 & Média & Alta \\
G502 & Média & Alta \\
G503 & Média & Alta \\
G504 & Média & Alta \\
G505 & Média & Alta \\
\hline
\end{tabular}


Estudos realizados por Kim e Bae (2010) demonstraram um aumento da atividade e da produção dessas células de defesa através da estimulação em acupontos específicos, melhorando, por conseguinte, o desempenho imune dos indivíduos. Takahashi et al. (2009), citaram que em sua pesquisa, a contagem de células CD16+ e CD56+, intimamente ligadas com a atividade das células NK, apresentaram níveis gradualmente aumentados em voluntários saudáveis, submetidos a acupuntura. Os mesmos autores também relataram o aumento de células $\mathrm{T}$ em indivíduos com várias doenças, onde cerca de $80 \%$ dos pacientes humanos tratados apresentaram um aumento significativo nos valores de CD4+e CD3+, 30 minutos após a acupuntura nos acupontos E36 (Zusanli) e IG4 (Hegu), e um aumento na contagem de células $\mathrm{T}$ da subpopulação CD8+, 24 horas após a estimulação. Bihari et al. (1995), realizaram um experimento onde foram utilizadas 12 cabras saudáveis, com idades entre dois e três anos no qual se avaliou a resposta imune desses animais após a inoculação de anticorpos contra Salmonella sp. e eletroestimulação em um grupo de acupontos, onde foi observado que o estímulo da acupuntura foi significativo na modulação da resposta imune.

Durante a análise dos dados obtidos neste trabalho, foi utilizado o teste não-paramétrico de Mann-Whitney U que é empregado para duas amostras independentes e que não admite uma distribuição normal. Este teste é ideal para avaliar este tipo de desenho amostral em que o número de amostras é irregular e, portanto, não podemos assumir uma distribuição normal dentro do universo amostral utilizado. Quando o teste foi aplicado para avaliar os achados da titulação dos anticorpos anti-CDV nos animais estudados nos tempos D0 e D12 com base nos dados expressos na Tabela 1, foi possível observar que os resultados para os dois grupos (D0 e D12) foram significativamente diferentes com $\mathrm{p}<0.5$, o que indica que podemos rejeitar a hipótese nula de que a distribuição dos dois grupos sejam idênticas.

\section{Conclusão}

Os resultados obtidos demonstram que a estimulação pela acupuntura eleva o título de anticorpos dos animais que tinham título médio contra cinomose, em todos os grupos experimentais, mesmo nos que não receberam a vacina, além de aprimorar os parâmetros leucométricos destes animais, corroborando aos achados da literatura de estimulação imunológica específica e inespecífica pela acupuntura. Os resultados apresentados são um ponto inicial de estímulo a pesquisas futuras que podem vir a estabelecer novas diretrizes acerca do uso da acupuntura na estimulação imunológica em animais.

\section{Conflito de Interesse}

Os autores declaram não existir conflito de interesse.

\section{Agradecimentos}

Ao Conselho Nacional de Desenvolvimento Científico e Tecnológico (CNPq) pelo auxílio financeiro. Ao médico veterinário João Marcelo Wanderley de Mendonça Uchôa Cavalcanti pelo apoio técnico no desenho experimental deste experimento.

\section{Referências}

Aoki, C.G. Metaloproteinases de matriz 2 e 9 no líquido cefalorraquidiano e soro de cães naturalmente infectados pelo vírus da cinomose. 2014. 44 f. Dissertação (Mestrado em Medicina Veterinária) - Programa de PósGraduação em Medicina Veterinária, Universidade Estadual Paulista.

Biazzono, L.; Hagiwara, M.R.; Corrêa, A.R. Avaliação da resposta imune humoral em cães jovens imunizados contra a cinomose com vacina de vírus atenuado. Brazilian Journal of Veterinary Research and Animal Science, 38(5): 245-250, 2001.

Bihari, A.W.; Kumar, A.; Garg, S.K. Enhancement of antibody production by electro-acupuncture in goats immunized with Salmonella typhimurium. Indian Journal of Animal Sciences, 6S (1); 6, 1995.

Bottecchia, R.J. Imunomodulação pelo "point injection" no acuponto "bai hui" em bovinos vacinados contra a brucelose e o carrapato Boophilus microplus (Canestrini, 1889). 2005. 145f. Tese (Doutorado em Produção Animal) - Programa de Pós-Graduação em Ciência Animal, Universidade Estadual do Norte Fluminense.

Brito, H.F.V.; Corat, M.A.F.; Santos, M.R.; Gilioli, R.; Passos, L.A.C.; Lancellotti, M.; Ferreira, F.; Min, L.L. Tratamento de sequelas neurológicas em cães, causadas por infecção pelo vírus da cinomose, através do transplante alogênico de células mononucleares de medula óssea. Revista Científica de 
Medicina Veterinária - Pequenos Animais e Animais de Estimação, 8(24): 26-29, 2010.

Carvalho, O.V.; Botelho, C.V.; Ferreira, C.G.T.; Scherer, P.O.; Soares-Martins, J.A.P.; Almeida, M.R.; Silva Júnior, A. Immunopathogenic and neurological mechanisms of canine distemper virus. Advances in Virology, 2012: 1-10, 2012.

Drummond, B.L. Acupuntura na modulação da produção sanguínea. 2009. 22f. Monografia (Especialização em Acupuntura Veterinária), Instituto Homeopático Jacqueline Peker.

Durval, D.; Ginger, U. Vaccine associated immune-mediated hemolytic anemia in the dog. Journal of Veterinary Internal Medicine, 10(5): 290-295, 1996.

Freitas-Filho, E.G.; Ferreira, M.R.A.; Dias, M.; Moreira, C.N. Prevalência, fatores de risco e associações laboratoriais para cinomose canina em Jataí-GO. Enciclopédia Biosfera, 10(18): 2356-2365, 2014.

Greene, C.E.; Appel, M.J. Canine distemper. In: Greene, C. E. (Eds.). Infectious diseases of the dog and cat. Philadelphia: Elsevier, p. 2541, 2006.

Hendrick, M.J.; Goldschmidt, M.H. Do injection site reactions induce fibrosarcomas in cats? Journal of the American Veterinary Medical Association, 199(8): 968, 1991.

Hogenesch, H.; Azcona-Olivera, J.; ScottMoncrieff, C.; Snyder, P.W.; Glickman, L.T. Vaccine-induced autoimmunity in the dog. Advances in Veterinary Medicine, 41: 733747, 1999.

Horzinek, M.C. Vaccine use and disease prevalence in dogs and cats. Veterinary Microbiology, 117(1): 2-8, 2006.

Jain, N.C. Essentials of veterinary hematology. Philadelphia: Lea \& Febiger, 1993.

Kaneko, J.J.; Harvey, J.W.; Bruss, M.L. (eds.). Clinical biochemistry of domestic animals. 5ed. New York: Academic Press, 1997.

Kim, M.S., Nam, T.C., Eletroencephalography (EEG) spectral edge frequency for assessing the sedative effect of acupuncture in dogs. Journal of Veterinary Medical Science, 68(4): 409-411, 2006.

Kim, S.K.; Bae, H. Acupuncture and immune modulation. Autonomic Neuroscience: Basic and Clinica, 157: 38-41, 2010.

Lignon, G.B.; Bottecchia, R.J. Efeitos da terapia de injeção em pontos de Acupuntura em coelhos. Comunicado Técnico EMBRAPA, 41: 1-2, 2000.

Maclachlan, N.J.; Dubovi, E.J. Fenner's veterinary virology. $4^{\mathrm{a}}$ ed.: Academic Press, 2011, 534 p.
Mangia, S.H.; Moraes, L.F.; Takahira, R.K.; Motta, R.G.; Franco, M.M.; Megid, J.; Silva, A.V.; Paes, A. C. Efeitos colaterais do uso da ribavirina, prednisona e DMSO em cães naturalmente infectados pelo vírus da cinomose. Pesquisa Veterinária Brasileira, 34(5): 449-454, 2014.

Marques, A.R.P.A. Terapia com células estaminais derivadas do tecido adiposo em cães com sequelas neurológicas da esgana. 2016. 84 f. Dissertação (Mestrado em Medicina Veterinária) - Programa de PósGraduação em Medicina Veterinária, Universidade Lusófona de Humanidades e Tecnologias.

Matthiesen, A.D. Acupuntura no tratamento da cinomose canina. 2004. 40 f. Monografia (Especialização em Acupuntura Veterinária). Programa de Pós-Graduação em Acupuntura Veterinária, Universidade Estadual Paulista.

Medeiros, R; Saad, M. Acupuntura: efeitos fisiológicos além do efeito placebo. O Mundo da Saúde, 33(1): 69-72. 2009.

Nunes, F.V. O uso da acupuntura no tratamento da anemia. 2010. 51 f. Monografia (Graduação em Medicina Veterinária). Graduação em Medicina Veterinária, Universidade Federal do Rio Grande do Sul.

Sherding, R.G. Cinomose canina. In: Bichard, D.V.M; Sherding, R.G. Manual Saunders: clínica de pequenos animais. 3.ed. São Paulo: Roca, p. 2048, 2008.

Silva, C.C.F. Acupuntura no tratamento da cinomose nervosa. 2011. 38 f. Monografia (Graduação em Medicina Veterinária). Universidade Federal do Rio Grande do Sul.

Smith, C.A. Are we vaccinating too much? Journal of American Veterinary Medical Association, 207(4): 421-425, 1995.

Takahashi, T.; Sumino, H.; Kanda, T.; Yamaguchi, N. Acupuncture modifies immune cells. Journal of Experimental \& Clinical Medicine, 1(1): 17-22, 2009.

Wolf, A. M. Canine and feline vaccination: protocols, products, and problems. In: PENN ANNUAL CONFERENCE, 110TH. Pennsylvania. Proceedings... Pennsylvania, 2010. p.16-29.

Yamaguchi, N.; Takahashi, T.; Sakuma, M.; Sugita, T.; Uchikawa, K.; Sakaihara, S.; Kanda, T.; Arai, M.; Kawakita, K. Acupuncture Regulates leukocyte Subpopulations in Human Peripheral Blood. Evidence-Based Complementary and Alternative Medicine, 4(4): 447-453, 2007. 